\title{
Posterolateral epidural supra-C2-root approach (PESCA) for biopsy of lesions of the odontoid process in same sitting after occipitocervical fixation and decompression-perioperative management and how to avoid vertebral artery injury
}

\author{
Patrick Haas $^{1}$ - Till-Karsten Hauser ${ }^{2}$ - Kosmas Kandilaris ${ }^{3} \cdot$ Sebastian Schenk $^{4} \cdot$ Marcos Tatagiba $^{1}$. \\ Sasan Darius Adib ${ }^{1}$ (D)
}

Received: 25 July 2020 / Revised: 29 October 2020 / Accepted: 28 December 2020 / Published online: 11 January 2021

(C) The Author(s) 2021

\begin{abstract}
This study aims to describe the posterolateral epidural supra-C2-root approach (PESCA), which might be a good alternative to the transoral, anterolateral, and other posterolateral approaches for biopsy of lesions of the odontoid process (OP). The preoperative planning of PESCA included computerized tomography (CT), CT-angiography, and three-dimensional reconstruction (if possible, even with three-dimensional print) to analyze the angle of the trajectory and the anatomy of the vertebral artery (VA). For PESCA, the patient is positioned under general anesthesia in prone position. In case of an osteolytic lesion with fracture of the OP, an X-ray is performed after positioning to verify anatomic alignment. In the first step, in case of instability and compression of the spinal cord, a craniocervical fusion and decompression is performed (laminectomy of the middle part of the $\mathrm{C} 1$ arc and removal of the lower part of the lateral $\mathrm{C} 1 \mathrm{arc}$ ). The trajectory is immediately above the $\mathrm{C} 2$ root (and under the upper rest of the lateral part of $\mathrm{C} 1 \mathrm{arc}$ ). Even if the trajectory is narrowed, it is possible to perform PESCA without relevant traction of the spinal cord. The vertical segment of V3 of the VA at the level of $\mathrm{C} 2$ is protected by the vertebral foramen, and the horizontal part of V3 is protected by the remnant upper lateral part of the $\mathrm{C} 1$ arc (in case of normal variants). PESCA might be a good choice for biopsy of selected lesions of the OP in same sitting procedure after craniocervical stabilization and decompression.
\end{abstract}

Keywords Odontoid process $\cdot$ Vertebral artery $\cdot$ Posterolateral approach $\cdot$ Craniovertebral junction $\cdot 3 \mathrm{D}$ print $\cdot$ Occipitocervical fusion

\section{Introduction}

Surgeries of lesions of the odontoid process (OP) are still a great challenge today due to the close relation of the different important neurovascular structures.

Sasan Darius Adib

sasan_adib2002@yahoo.de

Patrick Haas

Patrick.haas@med.uni-tuebingen.de

Till-Karsten Hauser

till-karsten.hauser@med.uni-tuebingen.de

Kosmas Kandilaris

Kosmas.kandilaris@med.uni-tuebingen.de

Sebastian Schenk

Sebastian.schenk@med.uni-tuebingen.de
Reddy et al. [25] concluded that usually three different approaches are used to C2 body and OP: (1) transoral approaches, (2) anterolateral, and (3) posterolateral (transpedicular) approaches.

Marcos Tatagiba

marcos.tatagiba@med.uni-tuebingen.de

1 Department of Neurosurgery, University of Tuebingen, Hoppe-Seyler-Str. 3, 72076 Tuebingen, Germany

2 Department of Neuroradiology, University of Tuebingen, Hoppe-Seyler-Str. 3, 72076 Tuebingen, Germany

3 Department of Neuropathology, University of Tuebingen, Hoppe-Seyler-Str. 3, 72076 Tuebingen, Germany

4 Department of Anesthesiology and Intensive Care Medicine, University of Tuebingen, Hoppe-Seyler-Str. 3, 72076 Tuebingen, Germany 
The transoral-transpharyngeal approach provides access to the lower clivus, foramen magnum, anterior arc of $\mathrm{C} 1$, and the underlying odontoid process or $\mathrm{C} 2$, but the rate of infection and postoperative swelling using this approach is as high as 32 $\%[8,13]$; in addition, the surgical field is narrowed and deep [6], and there is high rate of CSF fistula.

Meanwhile the anterolateral and posterolateral transpedicular approaches are technically demanding due to the close relation with vascular structures (especially the V3 segment of vertebral artery (VA)) and neural structures, and the little size of the pedicles of $\mathrm{C} 2$ [25]. Apart from these main approaches, a good number of other approaches have been described in literature such as the lateral transcondylar approach [29], submandibular and transmandibular approaches [19, 30], the extreme lateral approach [29,37], far lateral approach [11], and even open midline and posterior transdural approaches [1, 9]. There are also special percutaneous approaches for biopsy, kyphoplasty, and vertebroplasty of C2 (in particular anterolateral, transpedicular, transforaminal, paraspinal, posterolateral, translateral, far lateral $[14,27])$ and special endoscopic approaches (in particular endonasal [26], transcervical [26], transoral [12, 26, 35], and far lateral [16]).

Al-Mefty et al. [20] recommended the transcondylar variant of open approach "with the removal of condylar surface of atlas for resection of the OP as an alternative to the anterior approach." Türe et al. [37] demonstrated another posterolateral variant by transatlas access for the removal of the OP (extreme lateral-transatlas approach).

Riley et al. [26] were the first to recommend the METRx posterolateral approach, in which they did a small paravertebral incision and entered a METRx dilatator for a minimally invasive surgical approach for odontoid lesions.

Eissan and Eldin [6] showed that posterolateral approaches are associated with a high risk of VA injury, especially in case of bone drilling in this region. Geroge and Laurian [10] were the first to describe the techniques for the mobilization of VA. Eissa and Eldin [6] presented a new posterior midline approach that followed the same setting of occipitocervical fixation in a cadaver study (also with mobilization of VA). Even though interesting, they concluded that "one of the pitfalls and limitations of the study is the fact that many neurosurgeons still have a difficulty in exposure and mobilization of the vertebral artery even with this familial posterior approach." As a result, we could not find any clinical report about this approach in real patients. Is there a save corridor without direct contact to VA?

Our objective was then to find an approach that follows the same sitting of posterior stabilization and decompression to get to the odontoid process for biopsy of unclear lesions, without opening the dura and without contact with the vertebral artery.

Therefore, we want to present the posterolateral epidural supra-C2-root approach (PESCA).

\section{Methods}

\section{Case presentation}

A 72-year-old man presented with a 4-week history of headache and neck pain, with a weight loss of over $20 \mathrm{~kg}$ in 6 months. A computed tomography (CT) of the craniovertebral junction (CVJ) and the cervical spine was done, which revealed an osteolytic lesion of the odontoid with signs of instability (differential diagnosis (DD) metastasis, DD rheumatoid arthritis, DD spondylodiscitis) (Fig. 1 a and b). MRI was not possible due to the presence of a pacemaker.

As history, the patient had a mitral valve insufficiency and coronary heart disease, with stent implantation 11 months ago (the patient takes clopidogrel), had an arterial fibrillation with a pacemaker, was hypertensive, and had a renal insufficiency.

Firstly, he was given a Philadelphia collar and analgesics.

Because the patient had severe secondary diseases, we had to find a strategy to solve these problems in one surgery.

An approach through midline incision from posterolateral which can be done in same sitting during posterior craniocervical stabilization was necessary.

\section{Goals of surgery}

1. To prevent any new perioperative problem (thrombosis, bleeding, stent occlusion, new neurological symptoms)

2. Posterior stabilization of the $\mathrm{CVJ}(\mathrm{C} 0-\mathrm{C} 4$ : OC plate, pedicle screw $\mathrm{C} 2$, and mass laterals screw $\mathrm{C} 3$ and $\mathrm{C} 4$ ) due to instability with the risk of neurological impairment

3. Laminectomy $\mathrm{C} 1$ and enlargement of the foramen magnum for decompression

4. Biopsy of the odontoid lesion to ensure the correct diagnosis

5. Single session for all procedures (due to severe secondary diseases and additional risk of a second surgery)

\section{Reasons for PESCA}

We thought of different possibilities to attain our objectives with only one surgery. To attain the second and third objectives, a prone position and a posterior approach was needed. In order to attain all our objectives in one procedure (goal 5), we had to find a way to do a biopsy because of the posterior approach (goal 3). It was not possible to reach the lesion through a posterior lateral transpedicular approach (because it was not possible to reach the osteolytic part of the OP through the angle of the pedicle); thus, we looked for other possibilities.

In the case of the posterolateral approaches to the OP the most "dangerous" structures are the VA and the spinal cord. We had to find a safe trajectory as regards these two structures. 


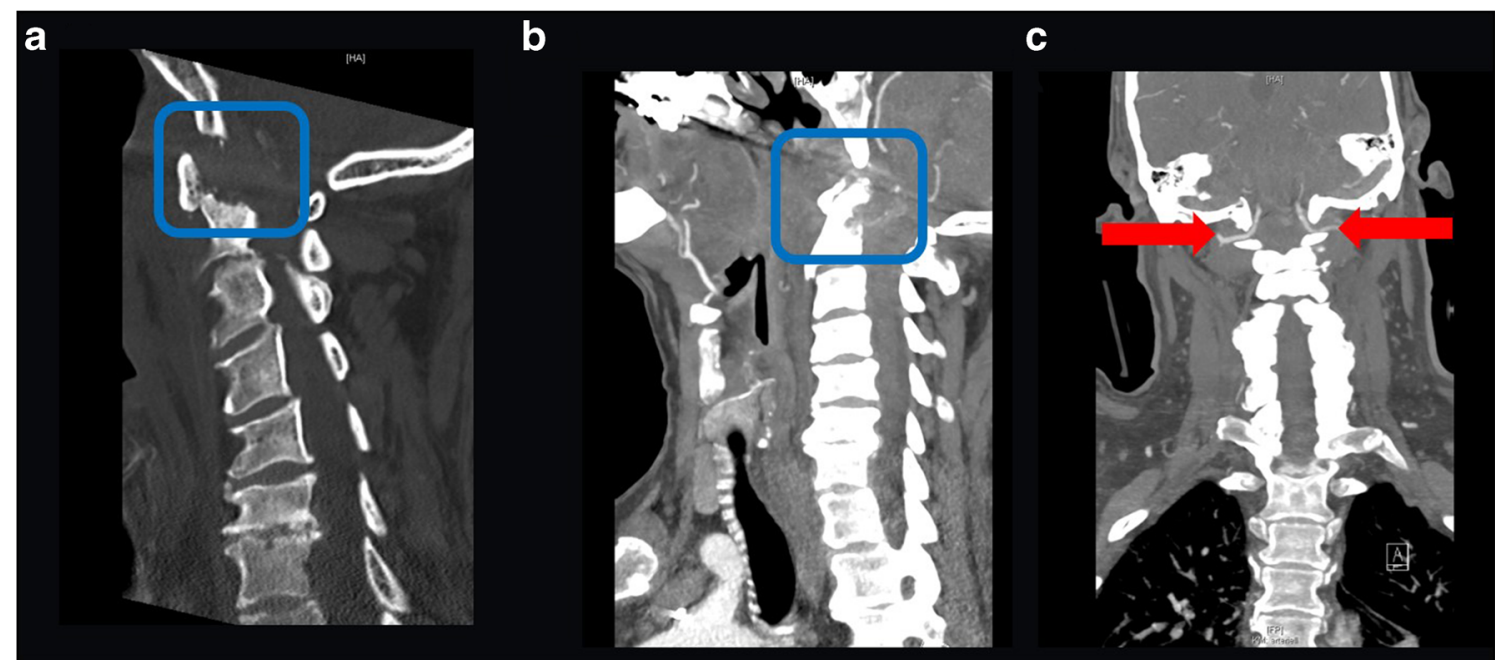

Fig. 1 Preoperative CT and CTA of cervical spine: a sagittal CT (bone window) revealed an osteolytic lesion of the OP (blue frame); b sagittal CT (soft tissue window) showed compression of spinal cord (blue frame);

Because of the serious secondary diagnoses, we planned a three-step surgery with the possibility of stopping at any step (even with partial attainment of the objective) depending on the occurrence of potential problems such as blood loss, cardiac, or pulmonary problems.

\section{Preoperative planning of strategy}

A thin sliced CT scan of the cervical spine for spinal neuronavigation and virtual 3-dimensional reconstruction was done.

A CT angiography (CTA) for analysis of the V3 segment of VA was done which revealed a "normal" anatomy of V3 segment (Fig. 1c).

Based on the thin-layer CT data set, a digital volume rendering model was generated. For preoperative planning of the safe biopsy corridor and simulation of the individual surgical steps, this data set was produced as a 1:1 scale model using the Fused Filament Fabrication (FFF, also known as 3D printing). The thermoplastic polyester polylactic acid (PLA) was used as a printing substance (filament).

The goal was to find the "safe" corridor. Different corridors were tried in the 3-dimensional model before surgery. A complex anesthesiological management was performed with normalization of coagulation.

\section{Surgical technique/surgical steps}

\section{Intervention}

The patient was positioned in a prone position under general anesthesia (head in a straight position, without rotation or inclination, due to instability and the risk of spinal cord injury) c coronal CT revealed "normal" variant of V3 segment of VA (VA runs over the posterior arch of $\mathrm{C} 1$ ) (red arrows)

in accordance to our standards. Cefuroxime was administered for perioperative surgical prophylaxis. An X-ray was done after positioning to verify anatomic alignment.

Intraoperative monitoring included sensory evoked potentials (SWP) and motor evoked potentials (MEP) of the upper and lower extremities.

We did a midline incision because posterior fusion and decompression were also done. A monopolar electrocautery could not be done due to the presence of the pacemaker. The inion, posterior wall of the posterior cranial fossa, $\mathrm{C} 1$ arc, and laminae $\mathrm{C} 2, \mathrm{C} 3$, and $\mathrm{C} 4$ were exposed.

\section{Step 1: fusion of the craniocervical junction CO-C4}

A C0 to $\mathrm{C} 4$ fusion was done in the first step with an OC plate (DePuy: Mountaineer). The pedicle screw C2 was placed under spinal neuronavigation (Brainlab) and at the level of $\mathrm{C} 3$, and C4 massa lateralis screws were inserted.

\section{Step 2: decompression}

An enlargement of foramen magnum was performed under the microscope (Carl Zeiss: kinevo) and a laminectomy of the medial $\mathrm{C} 1$ arc and the lower lateral part of $\mathrm{C} 1$ arc (subperiostal, with remnant upper $\mathrm{C} 1$ arc), and the removal of the left superior part of the left side of the arc of $\mathrm{C} 2$ and flavectomy was done (the distance between lateral upper $\mathrm{C} 1$ arc and inferior left part of C2 arc was around $1.5 \mathrm{~cm}$ ) (Fig. 2).

\section{Step 3: biopsy of the lesion of the odontoid process through PESCA}

Various landmarks such as $\mathrm{C} 2$ root, the remains of $\mathrm{C} 1$ arc, $\mathrm{C} 2$ arc, and the dural sac were identified. With the help of spinal 


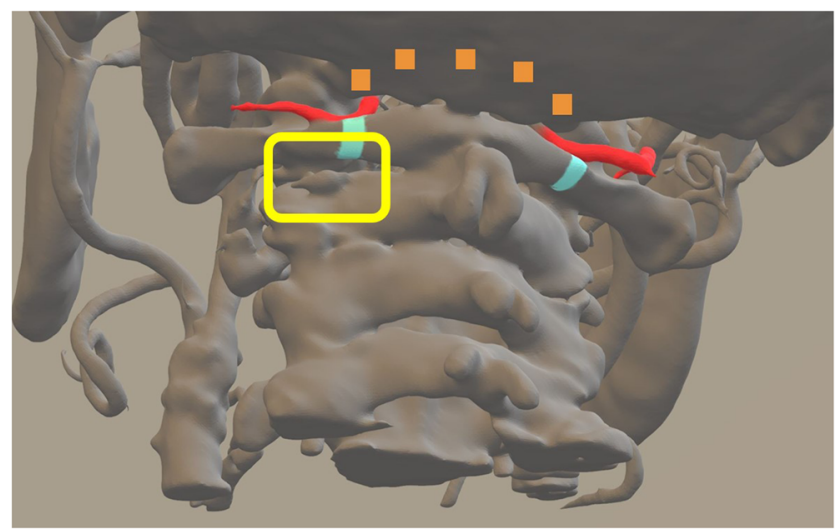

Fig. 2 3-Dimensional reconstruction of the cervical spine: red structures = vertebral arteries; orange squares $=$ enlargement of foramen of magnum; light blue squares = laminectomy of the medial part of $\mathrm{C} 1$, yellow frame $=$ entry zone for PESCA

neuronavigation, we checked our trajectory (especially the viewing and the working angle).

As close as possible to the superior part of $\mathrm{C} 2$ root, a dissector was carefully inserted with slight traction of the dural sac (under microscope and under IOM). The window between the rest of $\mathrm{C} 2$ arc, and C2 root was used as our approach (Fig. 3). Directly above the superior part of the $\mathrm{C} 2$ root was the entry point. The trajectory was located medial to pedicle of $\mathrm{C} 2$, medial to $\mathrm{C} 1-\mathrm{C} 2$ facet joint, and medial to tubercle for transverse ligament of atlas.
Using the left hand, the trajectory was slightly enlarged with a dissector by a slight touch to the dura, and with the right hand, a bioptic instrument was inserted under the microscope. The space needed had to be enough for just for one microinstrument. Due to dorsal decompression, the danger of compression was limited as much as possible. The IOM did not show any changes in MEP or SEP.

The OP was then exposed. A biopsy of the lateral portions of the lesions was done. The first intraoperative pathological analysis did not show a clear result; therefore, a second probe from the odontoid process was done, which revealed a spondylodiscitis without any signs of tumor or rheumatoid disease. After biopsy, the rest of $\mathrm{C} 1$ arc was removed. IOM remained stable during whole surgery.

\section{Postoperative course}

The patient recovered from surgery without any new deficits, but still with head and neck pain. A postoperative CT scan revealed a proper positioning of the screws and sufficient decompression of the spinal cord at the level of the CVJ (Fig. 4).

Pathologic examination of the mass showed a chronic recurrent spondylodiscitis without any signs of tumor (Fig. 5). An empiric antibiotherapy with clindamycin and ceftriaxone was started.
Fig. 3 a Sagittal CT (bone window): yellow lines = trajectory of PESCA. b Axial CT (bone window): yellow line = trajectory of PESCA. c 3Dimensional printing of the cervical spine (the inserted dissector demonstrates the entry point). d 3-Dimensional printing of the cervical spine: view of OP and foramen magnum (the inserted dissector demonstrates that PESCA is possible without relevant traction of the spinal cord)
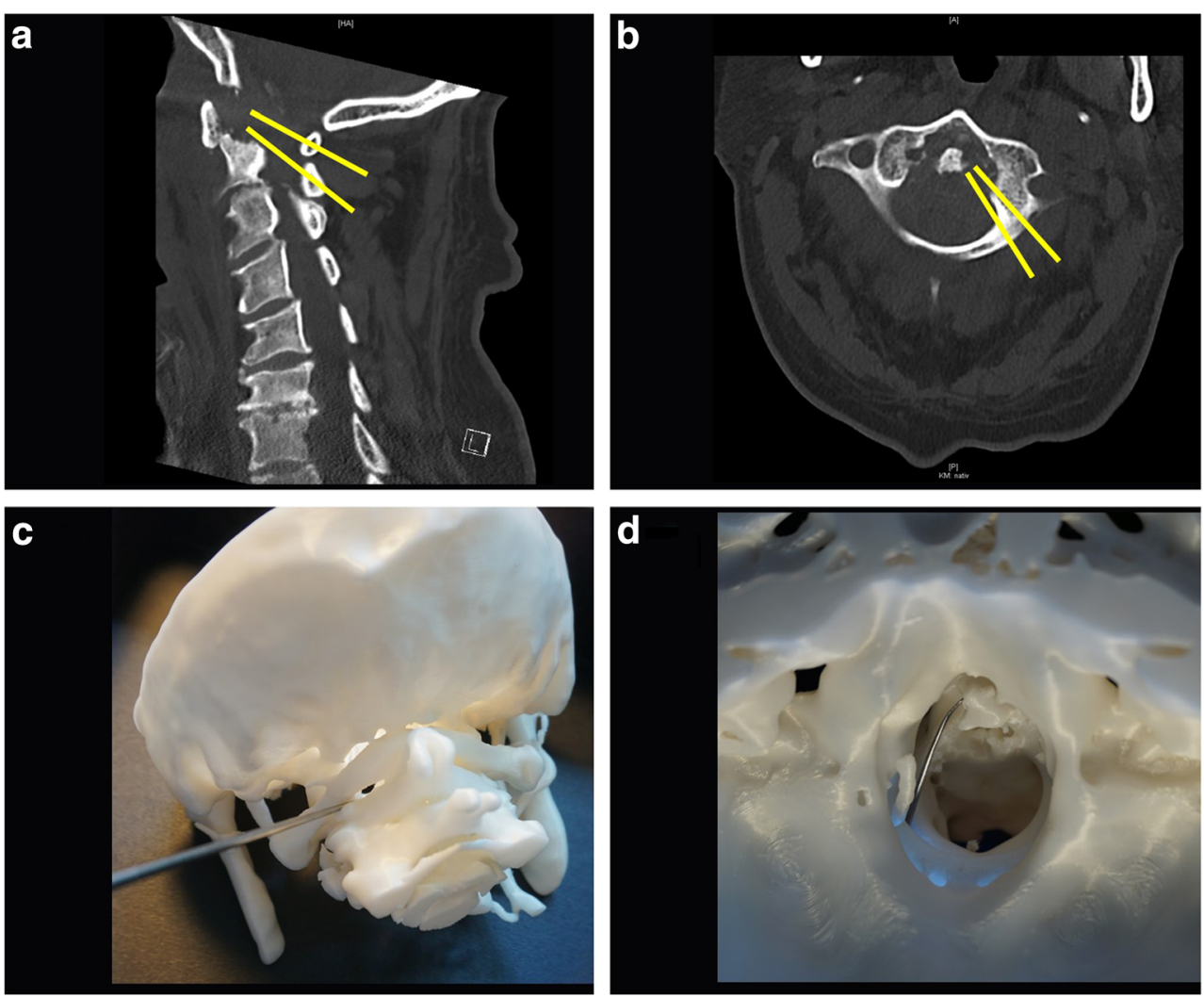


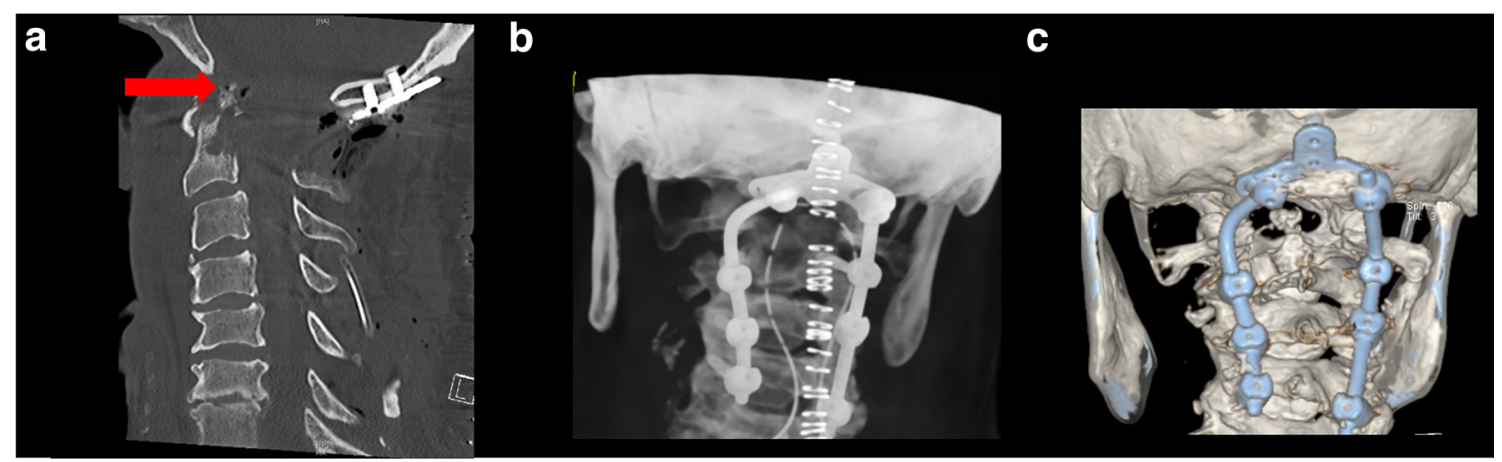

Fig. 4 Postoperative CT scan of cervical spine (a) and different 3-dimensional reconstruction (b,c) revealed a regular placement of screws and air in the OP from biopsy (red arrow)

After a few days, a wound revision was performed due to wound infection with screw loosening in the occipital plate, and screws with larger diameter were inserted.

Microbiological analysis of the probe and sore smears during the second surgery revealed Corynebacterium striatum with multiple resistance (even with resistance to clindamycin). Wound infection was caused by insufficient empiric antibiotherapy due to varying resistances of the very rare bacteria (Corynebacterium striatum) which was responsible for the spondylodiscitis of the $\mathrm{OP}$ and the secondary wound infection.

Retrospectively, the patient had a diabetic foot with wound infection one year ago, in addition to a number of other infections. Microbiological probes of the diabetic foot had also revealed Corynebacterium striatum with the same resistance; therefore, this seems to be the focus of spondylodiscitis of the OP.

These findings were the key to the successful treatment of the disease. The antibiotherapy was changed to vancomycine. Ten days after the initiation of vancomycine, the patient was transferred in a good condition with decreased infection parameters to his home hospital.

\section{Follow-up}

At follow-up examination 1 month after surgery, the patient did not manifest any neurological symptoms or symptoms of infection. The C-reactive protein level was $1.28 \mathrm{mg} / \mathrm{dl}$ (versus $11.62 \mathrm{mg} / \mathrm{dl}$ at 1 month ago). Wound healing was uneventful.
A CT scan of the cervical spine revealed postinfectional changes of the OP without further destruction of the OP, and there were no signs of screw loosening (Fig. $6 a$ and b).

\section{Discussion}

Reddy et al. [25] concluded that "lesions involving the dens and body of $\mathrm{C} 2$ are unique as it is quite challenging to approach these lesions for surgery or other interventions due to the close proximity to several important neural and vascular structures."

The study aimed to find a safe corridor to the OP for biopsy of indistinct lesions from the posterolateral approach, which can be used in the same setting as posterior stabilization and decompression, without opening of dura. Therefore, we developed the "posterolateral epidural supra-C2-root approach" (PESCA). For PESCA, we performed a medial $\mathrm{C} 1$ arc removal with drilling of the lower part of the lateral $\mathrm{C} 1 \mathrm{arc}$ (subperiostal, with remnant upper $\mathrm{C} 1$ arc) and $\mathrm{C} 2$ partial arc removal. The window between the rest of the $\mathrm{C} 2$ arc and the $\mathrm{C} 2$ root was used in our approach.

\section{Osteolytic lesions of the OP}

Rheumatoid arthritis is the main pathology which leads to osteolysis of the odontoid (approximately $58 \%$ to $72 \%$ of the cases). Spondylodiscitis of the odontoid is rare [4], but
Fig. 5 a,b Histopathologic findings of bioptic probe (hematoxylin-eosin stain), showing inflammatory tissue with neutrophil granulocytes, plasmocytes, and lymphocytes

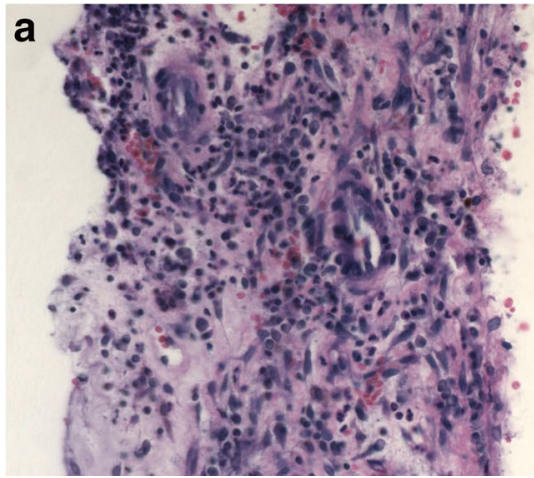


Fig. 6 Sagittal CT scan of the cervical spine (a soft tissue window; $\mathbf{b}$ bone window) revealed no postinfectional changes of the OP without further destruction of the OP and revealed no signs of screw loosening

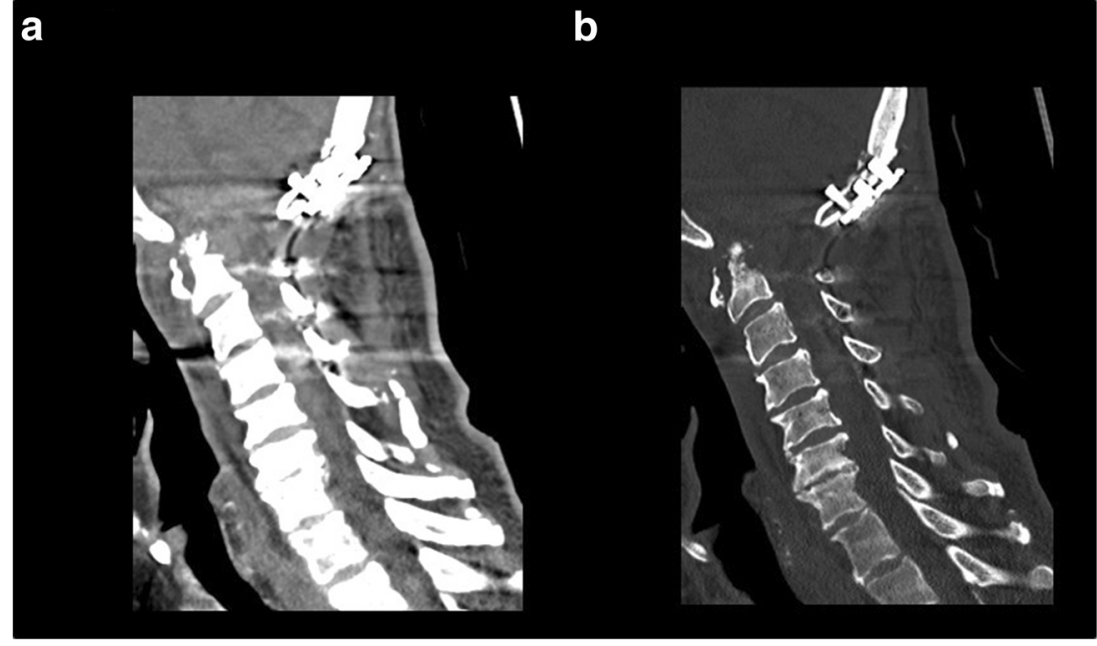

according to literature, the mortality rate is approximately onethird $[17,26,33]$. Tuberculosis is the most common infection in the atlantoaxial region [4].

The most nonspecific symptoms (such as neck pain, fever, and swelling of the neck) are common [4]. In our case, microbiological analysis of the probe and sore smears revealed the presence of Corynebacterium striatum with varying resistances (even resistant to clindamycin). A Corynebacterium infection of the OP is very rare.

\section{V3 segment of vertebral artery: anatomy, variants, and injury in cervical spine surgery}

One main objective was to search for an approach with a safe distance to VA (or even without contact to vertebral artery) to prevent VA injury. Therefore, the study of V3 segment of VA and its variants was an important part. The V3 segment of VA is located at the level of the craniocervical junction (CVJ) (from C-2 transverse process to the artery's entry through to the dura mater [39]) is anatomical complex [39, 40] and can be subdivided into 3 parts $[10,39]$.

Wakao et al. [40] concluded that VA injury "is one of the most serious complications arising from cervical spine procedures." The rate of VA injury during cervical spine surgery ranges from 0.3 to $8.2 \%$ in normal anatomy [15, 18, 21, 22].

Injury to the dominant VA (but sometimes also the nondominant VA) may result in severe complications such as a pseudoaneurysm, a formation of an arteriovenous fistula, VA occlusion, severe bleeding, stroke, or even death [39].

Different variants of the VA have been reported by different authors [28, 32, 36, 41, 42], and Ulm et al. [39] analyzed the different distances.

Wakao et al. [40] classified the different variants of the VA in the CVJ into (1) persistent first intersegmental artery (FIA) $(1.8 \%),(2)$ fenestration of the VA above and below $\mathrm{C} 1$ (FEN) $(1.3 \%),(3)$ posterior and inferior cerebellar artery (PICA) from C1/2 (1.3\%), and (4) high-riding VA (10.1\%). Li et al. [18] recommended a different classification with seven different types of variation of the VA at the CVJ. Tokuda et al. [36] and Yamazaki et al. [42] found a relationship between VA anomalies and anomalies of the CVJ (e.g., in case of Klippel-Feil syndrome).

In case of FIA and in case of FEN, PESCA is not a good choice. Patra et al. [24] showed that embryologically, the VA is formed by vertical channel interconnecting the cervical intersegmental arteries. Intersegmental arteries disappear while the vertical connections persist $[22,24]$.

Tokuda et al. [36] also showed in their series of 300 vertebral artery that in two cases, the VA runs under the posterior arch of C1 [31, 36], and Uchino et al. [38] reported a persistence of first intersegmental artery in up to $3.2 \%$ of normal subjects and an overall prevalence of CVJ-VA anomalies of $5 \%$. Before carrying out the PESCA, CTA of the vertebral artery is absolutely necessary.

In these cases (FIA and FEN), PESCA should not be done because of the high risk of VA injury.

\section{Advantages of the 3-dimensional printing}

Additive manufacturing, also known as 3D printing, is a rapidly emerging technology in the medical sector. Besides the production of patient-individual implants, patient education, or university teaching, 3D-printed models enable the detailed simulation of an upcoming operation or serve the development of new operation methods. Even they cannot replace an anatomical preparation, they offer the advantage of reproducing the individual site exactly and without great expenditure of time and money. Thermoplastic Fused Filament Fabrication (FFF) and photochemical polymerization using stereolithography (SLA, resin printing) have proven themselves for the production of anatomical models. They are available as desktop printers in a variety of different makes at low cost. More sophisticated 
processes such as selective laser sintering, on the other hand, require a much more complex infrastructure and are more reserved for applications such as the development of implants.

3D-printed models are not to be understood as competition to the purely digitally generated models. Rather, they are the logical continuation of digitization and thus enable the technological bridging back into a haptically oriented discipline such as neurosurgery.

The idea of PESCA was created using this 3-dimensional print and analyzing different potential corridors.

However, even if helpful, not every hospital has the capacity to perform $3 \mathrm{D}$ printing. With the abovementioned anatomical and radiological knowledge, PESCA can also be performed without preoperative 3D-printed model.

\section{Indications for PESCA}

PESCA provides a safe corridor. This approach is safe regarding the vertebral artery in normal constellation. At the level of $\mathrm{C} 2$ the vertebral artery is normally covered by bone and clearly away from the approach. The horizontal segment of V3 normally turns around the $\mathrm{C} 1$ arc. This means that under the $\mathrm{C} 1 \mathrm{arch}$, there is a safe entry zone.

In case of a necessary posterior fusion of $\mathrm{CVJ}$ with decompression with laminectomy of $\mathrm{C} 1$ (and partial resection of lamina $\mathrm{C} 2$, and possibly decompression of foramen magnum) due to an osteolytic lesion of the OP with instability, the PESCA can be a good choice, especially in patients with severe secondary diagnoses with the goal of only one surgery for fusion, decompression, and bioptic procedure.

The main advantage of the PESCA is that no secondary approach is needed (compared with transoral or anterolateral approaches). Furthermore, in the transoral approach, the rate of infection and postoperative swelling using this approach reaches up to $32 \%[8,13]$; in addition, the surgical field is narrowed and deep [6], and there is a high rate of CSF fistula. Moreover, the access may be limited by anatomical problems like plate size and location [26], and in many cases, an ENT co-surgeon is necessary [26]. In case of posterolateral transpedicular approaches, owing to the trajectory (because of the angle of the pedicle), the reachable target is limited, and it might be difficult to reach the upper parts of the OP. A further advantage of the PESCA, compared with the posterolateral transpedicular approaches, is that the surgeon works under a view.

Posterior transdural approaches are associated with a high risk for cerebrospinal fluid leakage and infections [26], and a previous study reported a risk of accessory nerve injury or vertebral artery injury [26].

Two structures should be kept in mind: (1) The dura sac with spinal cord and (2) the vertebral artery. Intraoperative monitoring with MEP and SEP might be of benefit to get an overview of the spinal cord function. In case of deterioration of MEP or SEP, the approach should be discontinued and another one decided upon.

A very careful planning of the trajectory should be done to make sure that the lesion of OP can be reached through PESCA.

A strong knowledge of the course of VA is absolutely necessary, especially with VA variations as focus (see below).

Different authors $[22,39]$ reported that the risk of intraoperative vertebral injury during surgeries of the CVJ can be reduced with the aid of preoperative imaging that included the evaluation of osseous cervical structures and vascular anatomy [39].

We recommend that CT with CTA and, if possible, MRI should be performed. In addition, 3-dimensional virtual reconstructions and/or 3-dimensional prints provide a major advantage in preoperative planning.

In very special anatomical constellation, a sonographic Doppler helps for a safe surgery.

\section{Enlargement of the posterolateral pathway to the OP: head positioning, sacrification of C2 (and/or C1)}

In our case, we did a medial $\mathrm{C} 1$ arc removal with drilling of the lower part of the lateral $\mathrm{C} 1 \mathrm{arc}, \mathrm{C} 2$ partial arc removal, and craniotomy for enlargement of foramen of magnum [30].

Positioning of the head might help to enlarge the anatomical window [26]. In our case, the odontoid was osteolytic, and consequently we positioned the head in straight position to prevent fracture of odontoid process with injury of spinal cord, furthermore, to be in right position for stabilization.

Depending on the anatomy, an infra-C2-root approach (instead of a supra-C2-root approach) might be discussed.

Even PESCA is a supra-C2-root approach, in case of a narrowed corridor of PESCA, a sacrifice of $\mathrm{C} 2$ root might be discussed, because mobilization of the $\mathrm{C} 2$ root can be difficult even for the most experienced surgeons [34].

But, sacrificing the $\mathrm{C} 2$ root should not be done generously, due to the fact that it might result in occipital hypesthesia [7] and in up to $25 \%$ of cases in neuropathic pain syndrome [3, 7]. However, Badhiwala et al. [3] summarized that there is a substantial heterogeneity in the outcomes of numbness and occipital pain after sacrifice of the $\mathrm{C} 2$ root in the literature [3]. They concluded that the studies are different regarding design, method of assessment of $\mathrm{C} 2$ function, and primary outcome [3]. Also, different techniques of $\mathrm{C} 2$ sacrification had been described, in case of $\mathrm{C} 1$ lateral mass screws, in literature [2, 7, 23], which might improve exposing of relevant anatomy. Besides monopolar [21, 34] and bipolar electrocautery [2, 43], also sharp division [23] has been described. Ligating the cut nerve ends has been reported [5]. Florman et al. [7] concluded that review of publications addressing the occurrence of postoperative neuralgia after $\mathrm{C} 2$ root division also reveals substantial variability in sectioning practice and 
reported that $\mathrm{C} 2$ neuralgia is rare in case of sharply dividing the $\mathrm{C} 2$ root with bipolar electrocautery [7]. Furthermore, the location of the $\mathrm{C} 2$ transection seems to be relevant [7]. $\mathrm{C} 2$ neuralgia seems to be rarer in case of dividing $\mathrm{C} 2$ root at the midportion of the ganglion where it overlies the $\mathrm{C} 1-2$ joint [7]. Furthermore, hemorrhage of the venous plexus during the procedure has been described as a potential risk [34].

In case of stabilization, also $\mathrm{C} 2$ arc removal could be discussed. In case of narrowed corridor using PESCA, drilling of lateral mass and/or mobilization of vertebral artery [6] would help to enlarge the pathway.

Riley et al. [26] were able to safely access the anterior epidural space, odontoid, and even retropharynx. In their approach, they passed between thecal sac and the $\mathrm{C} 1 / 2$ joint, but they used an approach $4 \mathrm{~cm}$ lateral to the midline and enter a METRc (Medtronic, Memphis, $\mathrm{TN}$ ) dilatator. The $\mathrm{C} 1$ inferior laminar edge was shaved down by $2-3 \mathrm{~mm}$ [26].

\section{Limitations}

In our opinion, PESCA is an approach used especially for biopsy of odontoid lesions, due to the fact that the corridor is very narrowed and the working angle is orientated up.

Removal of odontoid process is not possible. Furthermore, it is not suitable for anterior lesions of the OP.

In case of special constellation of anatomy of VA such as intersegmental VA, PESCA is contraindicated.

Due to the fact that slight traction of dural sac maybe necessary, PESCA should be only performed after previous decompression (enlargement of foramen of magnum and medial $\mathrm{C} 1$ laminectomy with drilling of the lower lateral $\mathrm{C} 1$ arc is furthermore necessary, and even partial removal of $\mathrm{C} 2 \mathrm{arc}$ ), and IOM is absolutely necessary.

In case of small $\mathrm{C} 1$ and $\mathrm{C} 2$ arc with close relation to each other, PESCA is not a good choice.

\section{Summary}

In summary, PESCA is a good approach for biopsy of lesions of the OP after CVJ fusion and laminectomy or subperiostal laminectomy of $\mathrm{C} 1$ and possibly partial removal of one side of $\mathrm{C} 2$ arc (and eventual scarification of root $\mathrm{C} 2$ ). Even a second surgery was necessary in our case because of a wound infection (due to insufficient empiric antibiotherapy before final microbiological analysis); we demonstrated that PESCA is possible in the same sitting after occipitocervical fixation and decompression.

The huge advantage of PESCA is that there is no direct contact to VA in case of "normal variant of VA" and in case of subperiostal C1 removal.
It is absolutely necessary to carry out a careful preoperative planning with CTA of vertebral artery; in addition, a 3dimensional print may help to get familiar with the individual anatomic situation. Even 3-dimensional virtual reconstructions are common today; the haptic printing will help the trajectory in a different way. Also, it may help to study the working angle to the OP. IOM is essential, and spinal neuronavigation will help to find the best trajectory. In a very special anatomical constellation, a sonographic Doppler might also support safe surgery.

A good team with experienced anesthetists and spinal surgeon is necessary.

It is important to recognize that this approach has a small corridor and a steep angle, but it is elegant, due to the fact, that you do not have to use a second approach after fusion and decompression.

Authors' contributions All authors listed have made substantial, direct, and intellectual contribution to the work and approved it for publications. PH performed analyses, 3D-print, and critical revision. TKH performed analyses and critical revision. KK performed analyses and critical revision. SS performed analyses and critical revision. MT performed analyses and critical revision. SDA gave idea and development of PESCA, performed analyses, wrote the article, and critical revision.

Funding Open Access funding enabled and organized by Projekt DEAL.

Data availability All data are included in the manuscript.

\section{Compliance with ethical standards}

Conflict of interest The authors declare that they have no conflict of interest.

Ethical approval All procedures performed in studies involving human participants were in accordance with the ethical standards of the institutional and/or national research committee (ethics committee of the University Hospital Tübingen, Germany; reference number 478/ 2020BO) and with the 1964 Helsinki Declaration and its later amendments or comparable ethical standards

\section{Consent to participate Written consent was obtained from patient.}

Consent for publication Written consent was obtained from patient.

Code availability Not applicable.

Open Access This article is licensed under a Creative Commons Attribution 4.0 International License, which permits use, sharing, adaptation, distribution and reproduction in any medium or format, as long as you give appropriate credit to the original author(s) and the source, provide a link to the Creative Commons licence, and indicate if changes were made. The images or other third party material in this article are included in the article's Creative Commons licence, unless indicated otherwise in a credit line to the material. If material is not included in the article's Creative Commons licence and your intended use is not permitted by statutory regulation or exceeds the permitted use, you will need to obtain 
permission directly from the copyright holder. To view a copy of this licence, visit http://creativecommons.org/licenses/by/4.0/.

\section{References}

1. Archer J, Thatikunta M, Jea A (2020) Posterior transdural approach for odontoidectomy in a child: case report. J Neurosurg Pediatr 25: 8-12. https://doi.org/10.3171/2019.7.PEDS19337

2. Aryan HE, Newman CB, Nottmeier EW, Acosta FL, Wang VY, Ames CP (2008) Stabilization of the atlantoaxial complex via C-1 lateral mass and $\mathrm{C}-2$ pedicle screw fixation in a multicenter clinical experience in 102 patients: modification of the Harms and Goel techniques. J Neurosurg Spine 8:222-229. https://doi.org/10. 3171/SPI/2008/8/3/222

3. Badhiwala JH, Nassiri F, Witiw CD, Mansouri A, Almenawer SA, Fehlings MG (2017) Does transection of the $C 2$ nerve roots during $\mathrm{C} 1$ lateral mass screw placement for atlantoaxial fixation result in a superior outcome?: a systematic review of the literature and metaanalysis. SPINE 42:E1067-E1076. https://doi.org/10.1097/BRS. 0000000000002069

4. Busche M, Bastian L, Riedemann NC, Brachvogel P, Rosenthal H, Krettek C (2005) Complete osteolysis of the dens with atlantoaxial luxation caused by infection with Staphylococcus aureus: a case report and review of the literature. Spine 30:E369-E374. https:// doi.org/10.1097/01.brs.0000168375.88129.3a

5. Dewan MC, Godil SS, Mendenhall SK, Devin CJ, McGirt MJ (2014) C2 nerve root transection during C1 lateral mass screw fixation: does it affect functionality and quality of life? Neurosurgery 74:475-480; discussion 480-481. https://doi.org/10. 1227/NEU.0000000000000306

6. Eissa EM, Eldin MM (2017) Odontoidectomy through posterior midline approach followed by same sitting occipitocervical fixation: a cadaveric study. J Craniovertebr Junction Spine 8:58-63. https://doi.org/10.4103/0974-8237.199879

7. Florman JE, Cushing DA, England EC, White E (2019) How to transect the $\mathrm{C} 2$ root for $\mathrm{C} 1$ lateral mass screw placement: case series and review of an underappreciated variable in outcome. World Neurosurg 127:e1210-e1214. https://doi.org/10.1016/j.wneu. 2019.04.100

8. Fourney DR, York JE, Cohen ZR, Suki D, Rhines LD, Gokaslan ZL (2003) Management of atlantoaxial metastases with posterior occipitocervical stabilization. J Neurosurg 98:165-170. https://doi. org/10.3171/spi.2003.98.2.0165

9. Fujiwara Y, Manabe H, Sumida T, Tanaka N, Hamasaki T (2015) Microscopic posterior transdural resection of cervical retroodontoid pseudotumors. J Spinal Disord Tech 28:363-369. https://doi.org/10.1097/BSD.0000000000000335

10. George B, Laurian C (1980) Surgical approach to the whole length of the vertebral artery with special reference to the third portion. Acta Neurochir 51:259-272. https://doi.org/10.1007/BF01406753

11. Heros RC (1986) Lateral suboccipital approach for vertebral and vertebrobasilar artery lesions. J Neurosurg 64:559-562. https://doi. org/10.3171/jns.1986.64.4.0559

12. Joaquim AF, Osorio JA, Riew KD (2019) Transoral and endoscopic endonasal odontoidectomies - surgical techniques, indications, and complications. Neurospine 16:462-469. https://doi.org/10. 14245/ns.1938248.124

13. Jones DC, Hayter JP, Vaughan ED, Findlay GF (1998) Oropharyngeal morbidity following transoral approaches to the upper cervical spine. Int J Oral Maxillofac Surg 27:295-298. https://doi.org/10.1016/s0901-5027(05)80618-6

14. Kaminsky IA, Härtl R, Sigounas D, Mlot S, Patsalides A (2013) Transoral C2 biopsy and vertebroplasty. Interv Med Appl Sci 5:7680. https://doi.org/10.1556/IMAS.5.2013.2.4
15. Katonis P, Papadakis SA, Galanakos S, Paskou D, Bano A, Sapkas G, Hadjipavlou AG (2011) Lateral mass screw complications: analysis of 1662 screws. J Spinal Disord Tech 24:415-420. https://doi. org/10.1097/BSD.0b013e3182024c06

16. Komatsu F, Komatsu M, Di Ieva A, Tschabitscher M (2013) Endoscopic far-lateral approach to the posterolateral craniovertebral junction: an anatomical study. Neurosurg Rev 36: 239-247; discussion 247. doi: https://doi.org/10.1007/s10143-012$0433-\mathrm{y}$

17. Lam CH, Ethier R, Pokrupa R (1996) Conservative therapy of atlantoaxial osteomyelitis. A case report. Spine 21:1820-1823. https://doi.org/10.1097/00007632-199608010-00021

18. Li T, Yin Y-H, Qiao G-Y, Wang H-W, Yu X-G (2019) Threedimensional evaluation and classification of the anatomy variations of vertebral artery at the craniovertebral junction in 120 patients of basilar invagination and atlas occipitalization. Oper Neurosurg (Hagerstown) 17:594-602. https://doi.org/10.1093/ons/opz076

19. Logroscino CA, Casula S, Rigante M, Almadori G (2004) Transmandible approach for the treatment of upper cervical spine metastatic tumors. Orthopedics 27:1100-1103

20. al-Mefty O, Borba LA, Aoki N, Angtuaco E, Pait TG (1996) The transcondylar approach to extradural nonneoplastic lesions of the craniovertebral junction. J Neurosurg 84:1-6. https://doi.org/10. 3171/jns.1996.84.1.0001

21. Molinari RW (2014) Commentary on: "Vertebral artery anomalies at the craniovertebral junction: a case report and review of the literature.” Evid Based Spine Care J 5:126. doi: https://doi.org/10. 1055/s-0034-1386757

22. Moon BJ, Choi KH, Shin DA, Yi S, Kim KN, Yoon DH, Ha Y (2018) Anatomical variations of vertebral artery and C2 isthmus in atlanto-axial fusion: consecutive surgical 100 cases. J Clin Neurosci 53:147-152. https://doi.org/10.1016/j.jocn.2018.04.058

23. Patel AJ, Gressot LV, Boatey J, Hwang SW, Brayton A, Jea A (2013) Routine sectioning of the $\mathrm{C} 2$ nerve root and ganglion for $\mathrm{C} 1$ lateral mass screw placement in children: surgical and functional outcomes. Childs Nerv Syst 29:93-97. https://doi.org/10.1007/ s00381-012-1899-1

24. Patra DP, Salunke PS, Sahoo SK, Ghuman MS (2015) Redundant anomalous vertebral artery in a case of congenital irreducible atlantoaxial dislocation: emphasizing on the differences from the first intersegemental artery and operative steps to prevent injury while performing C1-2 joint manipulation. Ann Neurosci 22:245247. https://doi.org/10.5214/ans.0972.7531.220412

25. Reddy AS, Dinobile D, Orgeta JE, Peri N (2009) Transoral approach to CT-guided C2 interventions. Pain Physician 12:253-258

26. Riley K, Singh H, Meyer SA, Jenkins AL (2016) Minimally invasive surgical approach for odontoid lesions: a technical description in a case of high cervical osteomyelitis and abscess. World Neurosurg 91:332-339. https://doi.org/10.1016/j.wneu.2016.04. 028

27. Rodriguez-Catarino M, Blimark C, Willén J, Mellqvist U-H, Rödjer S (2007) Percutaneous vertebroplasty at C2: case report of a patient with multiple myeloma and a literature review. Eur Spine J 16(Suppl 3):242-249. https://doi.org/10.1007/s00586-006-0256-Z

28. Salunke P, Sahoo SK (2018) Safeguarding the anomalous vertebral artery while dissecting, drilling, and instrumentation of $\mathrm{C} 1-2$ joint for congenital atlantoaxial dislocation: 2-dimensional operative video. Oper Neurosurg (Hagerstown) 15:E57. https://doi.org/10.1093/ ons/opy101

29. Sen CN, Sekhar LN (1991) Surgical management of anteriorly placed lesions at the craniocervical junction-an alternative approach. Acta Neurochir 108:70-77. https://doi.org/10.1007/ BF01407670

30. Serban D, Calina NA, Exergian F, Podea M, Zamfir C, Morosanu E, Giovani A, Checiu G (2012) The upper cervical spine tumor 
pathology C1-C2 - therapeutic attitude. Romanian Neurosurgery 19:251-263. https://doi.org/10.2478/v10282-012-0012-3

31. Sharma RR, Parekh HC, Prabhu S, Gurusinghe NT, Bertolis G (1993) Compression of the C-2 root by a rare anomalous ectatic vertebral artery. Case report. J Neurosurg 78:669-672. https://doi. org/10.3171/jns.1993.78.4.0669

32. Sivaraju L, Mani S, Prabhu K, Daniel RT, Chacko AG (2017) Three-dimensional computed tomography angiographic study of the vertebral artery in patients with congenital craniovertebral junction anomalies. Eur Spine J 26:1028-1038. https://doi.org/10.1007/ s00586-016-4580-7

33. Spies EH, Stücker R, Reichelt A (1999) Conservative management of pyogenic osteomyelitis of the occipitocervical junction. Spine 24:818-822. https://doi.org/10.1097/00007632-199904150-00015

34. Squires J, Molinari RW (2010) C1 lateral mass screw placement with intentional sacrifice of the $\mathrm{C} 2$ ganglion: functional outcomes and morbidity in elderly patients. Eur Spine J 19:1318-1324. https://doi.org/10.1007/s00586-010-1452-4

35. Tang X, Wu X, Tan M, Yi P, Yang F, Hao Q (2019) Endoscopic transnasal anterior release and posterior reduction without odontoidectomy for irreducible atlantoaxial dislocation. J Orthop Surg Res 14:119. https://doi.org/10.1186/s13018-019-1167-0

36. Tokuda K, Miyasaka K, Abe H, Abe S, Takei H, Sugimoto S, Tsuru M (1985) Anomalous atlantoaxial portions of vertebral and posterior inferior cerebellar arteries. Neuroradiology 27:410-413. https:// doi.org/10.1007/BF00327604

37. Türe U, Pamir MN (2002) Extreme lateral-transatlas approach for resection of the dens of the axis. J Neurosurg 96:73-82. https://doi. org/10.3171/spi.2002.96.1.0073

38. Uchino A, Saito N, Watadani T, Okada Y, Kozawa E, Nishi N, Mizukoshi W, Inoue K, Nakajima R, Takahashi M (2012) Vertebral artery variations at the $\mathrm{C} 1-2$ level diagnosed by magnetic resonance angiography. Neuroradiology 54:19-23. https://doi.org/ 10.1007/s00234-011-0849-z

39. Ulm AJ, Quiroga M, Russo A, Russo VM, Graziano F, Velasquez A, Albanese E (2010) Normal anatomical variations of the $V_{3}$ segment of the vertebral artery: surgical implications. J Neurosurg Spine 13:451-460. https://doi.org/10.3171/2010.4.SPINE09824

40. Wakao N, Takeuchi M, Nishimura M, Riew KD, Kamiya M, Hirasawa A, Kawanami K, Imagama S, Sato K, Takayasu M (2014) Vertebral artery variations and osseous anomaly at the C12 level diagnosed by 3D CT angiography in normal subjects. Neuroradiology 56:843-849. https://doi.org/10.1007/s00234-014$1399-\mathrm{y}$

41. Wang S, Wang C, Liu Y, Yan M, Zhou H (2009) Anomalous vertebral artery in craniovertebral junction with occipitalization of the atlas. Spine 34:2838-2842. https://doi.org/10.1097/BRS. 0b013e3181b4fb8b

42. Yamazaki M, Okawa A, Furuya T, Sakuma T, Takahashi H, Kato K, Fujiyoshi T, Mannoji C, Takahashi K, Koda M (2012) Anomalous vertebral arteries in the extra- and intraosseous regions of the craniovertebral junction visualized by 3 -dimensional computed tomographic angiography: analysis of 100 consecutive surgical cases and review of the literature. Spine 37:E1389-E1397. https://doi.org/10.1097/BRS.0b013e31826a0c9f

43. Yeom JS, Buchowski JM, Kim H-J, Chang B-S, Lee C-K, Riew KD (2013) Postoperative occipital neuralgia with and without C2 nerve root transection during atlantoaxial screw fixation: a post-hoc comparative outcome study of prospectively collected data. Spine J 13:786-795. https://doi.org/10.1016/j.spinee.2013.04.006

Publisher's note Springer Nature remains neutral with regard to jurisdictional claims in published maps and institutional affiliations. 